Case report

\title{
A very rare coronary artery anomaly: Twin circumflex arteries associated with acute coronary syndrome - two cases report
}

\author{
Berat Uğuz ${ }^{*}, 1$, Selma Kenar Tiryakioğlu ${ }^{1}$, Selvi Öztaş ${ }^{1}$, Alper Karakuş² \\ ${ }^{1}$ Department of Cardiology, Bursa City Hospital, Bursa, Turkey; ${ }^{2}$ Department of Cardiology, University \\ of Adiyaman, School of Medicine, Adiyaman, Turkey
}

\footnotetext{
Abstract

Circumflex coronary artery anomalies are the most common type so far observed. However, a dual origin of the circumflex is an extremely rare anomaly. We describe two different patients admitted to our clinic with acute coronary syndrome at the same day. Angiography revealed twin circumflex arteries: one from the left main artery and the other from the proximal right coronary artery.

Keywords: twin circumflex coronary artery; acute coronary syndrome; coronary artery anomaly.
}

\section{Introduction}

The increasingly extended use of diagnostic coronary angiography is discovering numerous congenital anomalies of the coronary arteries. At first, they were considered simple angiographic findings and there was a tendency to characterize them as benign [1, 2]. However, this attitude was undermined by reports of cases of sudden death, acute myocardial infarction, angina and syncope associated with their presence $[3,4]$. A dual origin of the circumflex artery $(\mathrm{Cx})$ is an extremely rare anomaly. The incidence of such as coronary anomalies is relevant not only for educational attentions but, more importantly, for public health issues. We describe two different patients admitted to our clinic with acute coronary syndrome at the same day.

Received: May 2020; Accepted after review: July 2020; Published: August 2020.

${ }^{*}$ Corresponding author: Berat Uğuz, Cardiology Department, Bursa City Hospital, Dogankoy Mah. Gumus Cad. No:10 Nilufer, Bursa,Turkey, 16110.

Email: beratuguz33@hotmail.com

\section{Case report}

First case, a 65-year-old man with an eight hours history of chest pain was referred to our clinic. He had no history of coronary artery disease, and alcohol or drug use. The only risk factor for atherosclerosis was hypertension.

His physical examination, echocardiogram except left ventricular hypertrophy were all normal. The electrocardiogram showed STsegment depression in leads V3-V6 and D1aVL (Figure1A). Findings of blood tests were unremarkable except for increases in cardiac enzymes. The patient was transferred to our catheterization laboratory for diagnostic coronary arteriography.

Conventional angiography revealed no significant stenosis of the left anterior descending coronary artery (LAD) and the left Cx artery, however intermediate artery (IM) had critical stenosis (Figure 1B). Surprisingly, right coronary angiogram showed an additional $\mathrm{Cx}$ artery and a right coronary artery (RCA) arising separately from the right sinus of Valsalva (Figure 1C). Both of them had non obstructive plaques. Thereafter, stenting was successfully performed for the IM artery stenosis. 


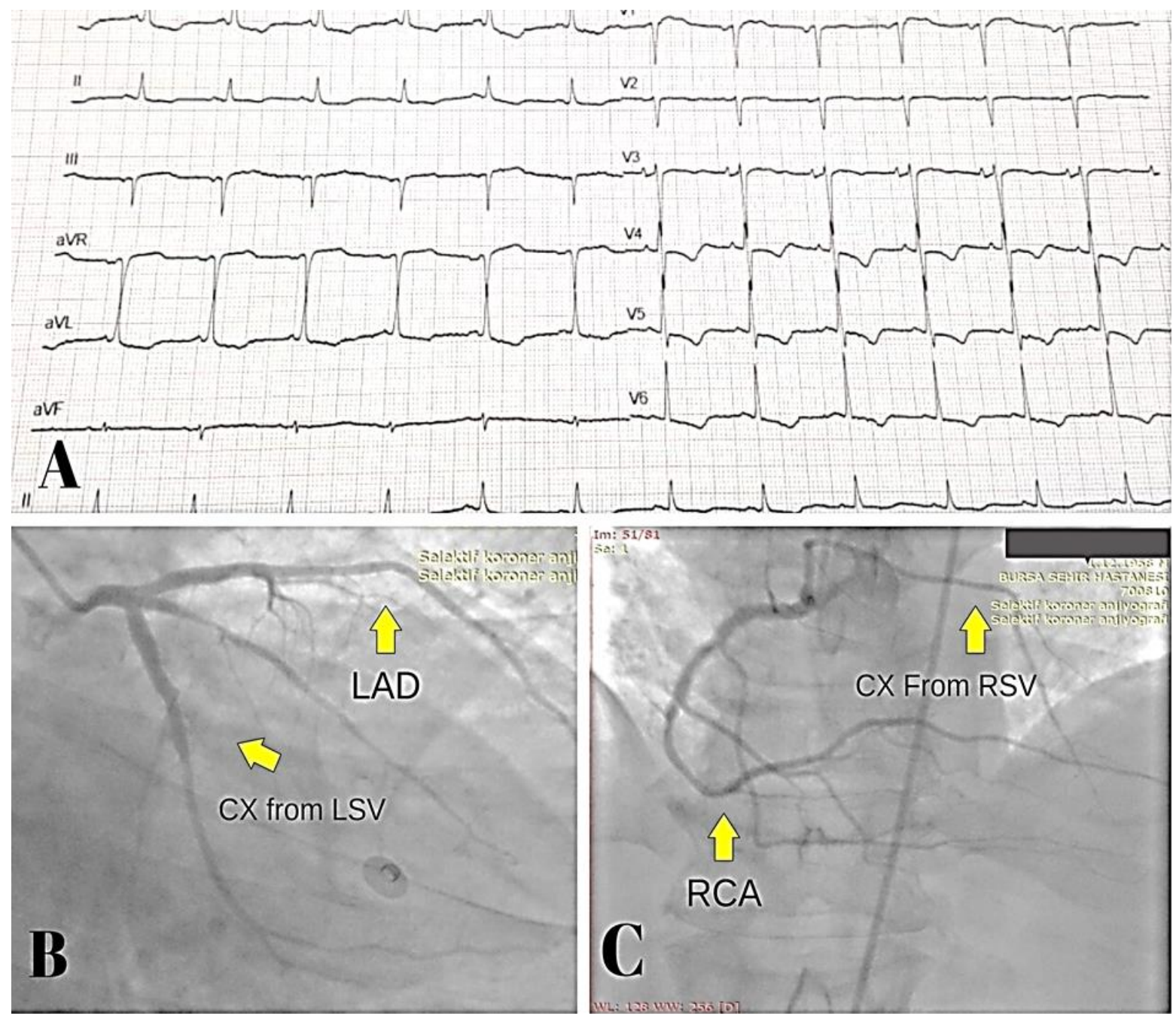

Fig. 1. A. The electrocardiogram showed ST-segment depression in leads V3-V6 and D1-aVL. B. Coronary angiogram in the right caudal view shows the left coronary artery, circumflex artery and intermediate artery. C. Coronary angiogram in the left anterior oblique cranial view shows the circumflex artery and right coronary artery originating from right sinus of Valsalva. (CX: circumflex artery, IM: Intermediate artery, LAD: left anterior descending artery, LSV: Left sinus of Valsalva, RCA: Right coronary artery, RSV: Right sinus of Valsalva)

Second case, a 49-year-old man had history of chest pain for four hours and high troponin levels was referred to our clinic. The only risk factor for atherosclerosis was smoking.

His physical examination, echocardiogram, and electrocardiogram (Figure 2) reports were all normal. Following physical examination and initial tests, a diagnostic coronary arteriography was performed.

Angiography revealed that no significant stenosis of the LAD and the left Cx artery
(Figure 3A). Right coronary angiogram showed an additional $\mathrm{Cx}$ artery and a RCA arising separately from the right sinus of Valsalva (Figure 3B-3C). The right $\mathrm{Cx}$ artery had significant stenosis and performed stenting (Figure 3D).

The post-interventional period was in a good condition for both of the patients, and the patients was followed up for 3 days and discharged without any complications. 


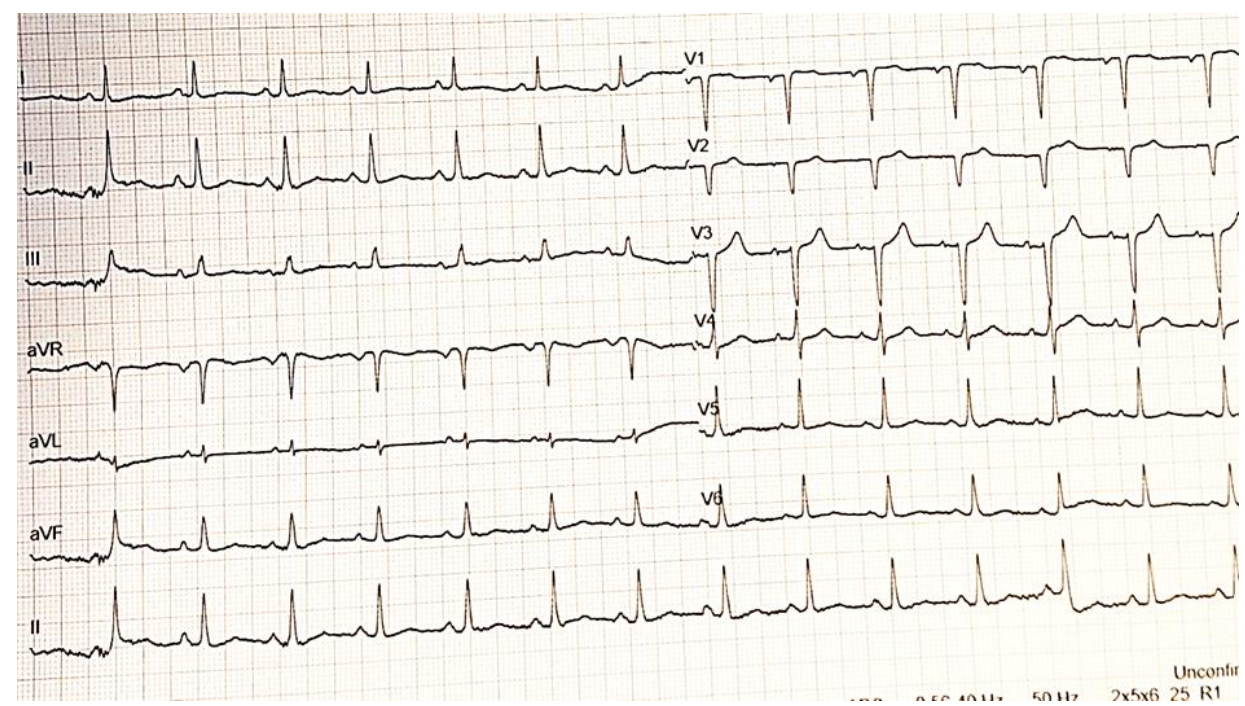

Fig. 2. The electrocardiogram showed no ST-segment depression or elevation
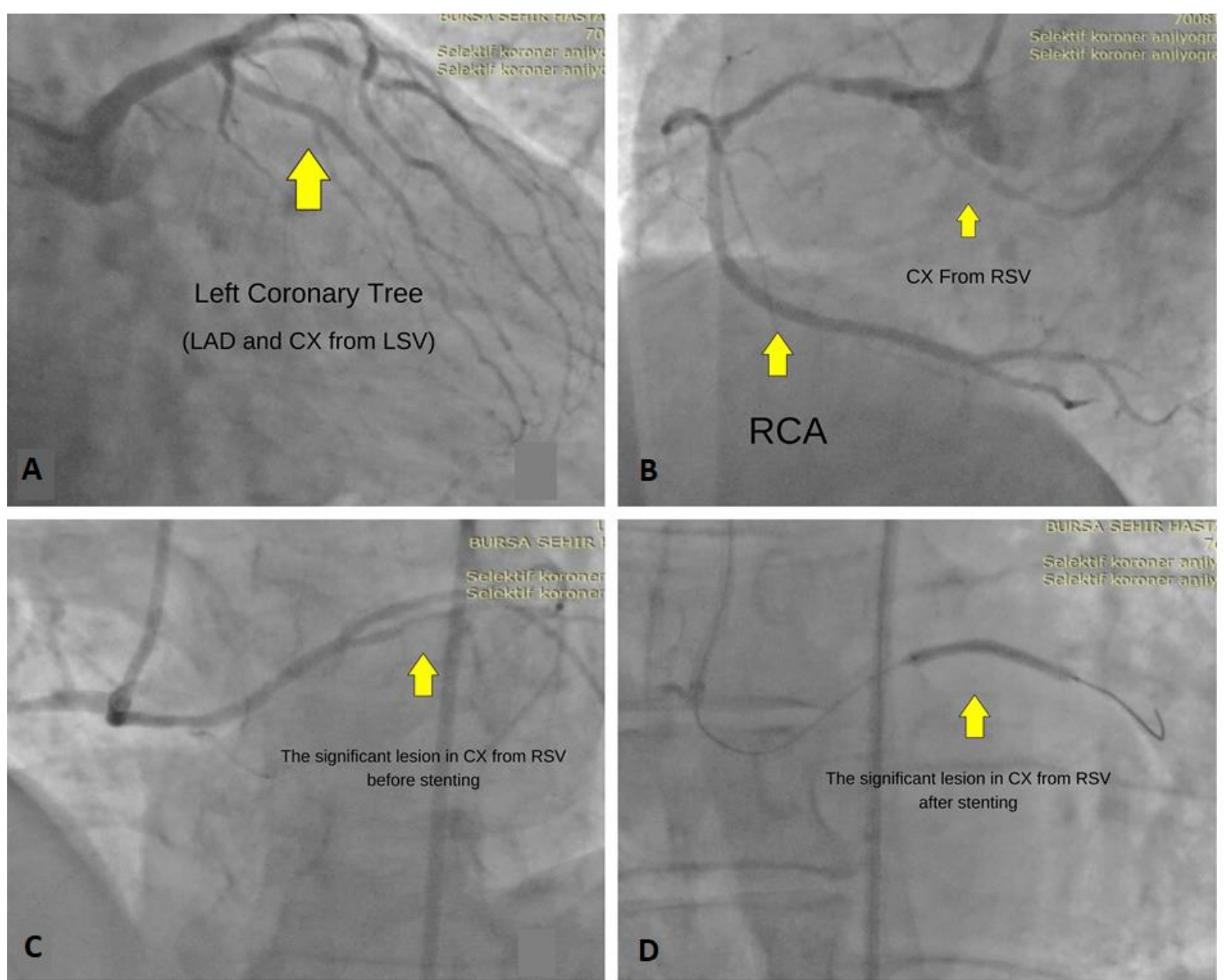

Fig. 3. A. Coronary angiogram in the left caudal view shows the left coronary artery tree with a circumflex artery. B. Coronary angiogram in the left anterior oblique cranial view shows the circumflex artery and right coronary artery originating from right sinus of Valsalva. C. The significant lesion, in the left anterior oblique cranial view, shows the circumflex originating from right sinus of Valsalva. D. After stenting the significant lesion, in left anterior oblique view shows the circumflex artery originating from right sinus of Valsalva (CX: circumflex artery, LAD: left anterior descending artery, LSV: Left sinus of Valsalva, RCA: Right coronary artery, RSV: Right sinus of Valsalva) 


\section{Discussion}

Coronary artery anomalies are found in 0.6$1.5 \%$ of coronary angiograms [1]. Although most of them have no clinical significance, they may cause acute myocardial damage and/or chronic injuries in the area supplied by the anomalous coronary artery arising from the incorrect coronary sinus of Valsalva [5]. Some coronary artery anomalies may cause chest pain, arrhythmia, heart failure and sudden death [6]. Myocardial ischemia can occur because of earlier and more aggressive atherosclerosis compared to a normal coronary artery [7]. That was found exclusively in anomalous vessels arising from the right side with a retroaortic course [8].

The most frequently found anomalies include a $\mathrm{Cx}$ artery with a separate ostium from the LAD originating in the left coronary cusp, an origin of the $\mathrm{Cx}$ artery taking off from the RCA or arising separately from the right coronary cusp [1]. This anomaly is thought to be benign and is usually clinically silent. However, it was observed in the Coronary Artery Surgery Study that the incidence of stenosis was greater in the $\mathrm{Cx}$ arteries originating from the right coronary sinus compared to normal Cx arteries originating from the left main coronary artery. There have been many reports of anomalous coronary arteries and their association with accelerated atherosclerosis resulting in myocardial infarction and sudden death, depending upon their origin, course, and termination $[2,9,10]$. The incidence of $\mathrm{Cx}$ anomalies is summarized in Table $1[1,8,11]$.

Table 1. The incidence of $C X$ anomalies

Circumflex Artery Anomaly

\begin{tabular}{l|c}
\hline Separate origin of LAD and CX in LSV & $0,7^{1}$ \\
\hline CX from RSV or RCA & $0,37^{1}$ \\
\hline Absent CX & $0,003^{8}$ \\
\hline Intercoronary communication (CX-RCA) & $0,002^{11}$ \\
\hline Congenital ostial stenosis or atresia of CX & $0,001^{11}$ \\
\hline CX - PA/RV fistula & $0,02^{11}$ \\
\hline Others & $0,2^{1}$ \\
\hline CX: Circumflex, LAD: Left anterior descending, LSV: Left sinus Valsalva, PA: Pulmonary artery, \\
RCA: Right coronary artery, RV: Right ventricle
\end{tabular}

Dual connection of the LAD to the left main coronary artery and the RCA is an extremely rare congenital coronary anomaly. This anomaly was classified into four types by Spindola-Franko et al. Double LAD type 1 is the most common. They found an incidence of about $1 \%$ for the type 1 in normal heart. Double RCA is also a very rare congenital coronary anomaly. There is not enough studies regarding double RCA in literature. Double RCA has been reported as case reports in only a few papers $[12,13]$.

The anomalous origin of the $\mathrm{Cx}$ artery from the proximal right coronary artery or from the right sinus of Valsalva was first described by Antopol and Kugalin 1933 [14]. There have been only 7 previously reported cases of bilaterally arising twin $\mathrm{Cx}$ arteries: one $\mathrm{Cx}$ artery arose from the left main coronary artery and the others from the right aortic sinus ( 3 cases) or the ostium of the right coronary artery (4 cases) following thereafter a retroaortic course to the left. In 2008 [15-19), Attar et al. reported a case of twin Cx arteries: one from the left main artery and the other one originated from the right coronary sinus [15]. Along the same lines, Van der Velden et al. presented a case with the coexistence of coronary fistulae and twin $\mathrm{Cx}$ arteries [16]. Elsewhere, Karabay et al. presented a case of twin $\mathrm{Cx}$ arteries arising from the left and right coronary systems with acute inferior myocardial infarction treated via percutaneous coronary intervention [5]. In a study by Cicek et al. there were significant stenoses at both of the twin $\mathrm{Cx}$ arteries, leading to heart failure [17]. Andreou et al. reported a case for preoperative identification of this anomaly in patients undergoing aortic valve 
surgery [18]. Another investigation by Otlu et al. reported transradial percutaneous coronary intervention in a patient with twin $\mathrm{Cx}$ arteries [19]. In this case report, we described two patients with twin $\mathrm{Cx}$ arteries: one originating from the left main coronary artery and the other one, a Cx, arising from the proximal part of the right coronary artery. Additionally, one of our case had critical right $\mathrm{Cx}$ stenosis.

\section{Conclusion}

The most important problem in diagnosing double $\mathrm{Cx}$ arteries the separate origin of the two Cx arteries from different ostia on the left or right aortic sinus of Valsalva. In the absence of

\section{References}

1. Yamanaka $O$, Hobbs RE. Coronary artery anomalies in 126,595 patients undergoing coronary arteriography. Cath Cardiovasc Diagn 1990; 21(1):28-40.

2. Wilkins CE, Betancourt B, Mathur VS, et al. Coronary artery anomalies: a review of more than 10,000 patients from the Clayton Cardiovascular Laboratories. Tex Heart Inst $J$ 1988; 15(3):166-173.

3. Roberts WC. Major anomalies of coronary arterial origin seen in adulthood. Am Heart $J$ 1986; 111(5):941-963.

4. Taylor AJ, Byers JP, Cheitlin MD, Virmani R. Anomalous right or left coronary artery from the contralateral coronary sinus: «high risk» abnormalities in the initial coronary artery course and heterogeneous clinical outcomes. Am Heart J 1997; 133:428-435.

5. Karabay KO, Uysal E, Bağırtan B, Vural M. A case of twin circumflex arteries associated with acute myocardial infarction. Turk Kardiyol Dern Ars 2010; 38:496-498.

6. Cicek D, Gokay S, Eldem HO, Muderrisoglu $\mathrm{H}$. Significant stenoses of twin circumflex arteries accompanied by heart failure: a rare coronary artery anomaly. Clin Pract 2011; 1(2):e22.

7. Carmlo V, Toste J, Castela S, et al. Anomalous origin of the circumflex coronary artery--two case reports. Rev Port Cardiol 2007; 26(78):789-793.

8. Samarendra P, Kumari S, Hafeez M, Vasavada BC, Sacchi TJ. Anomalous circumflex coronary artery: benign or predisposed to selective atherosclerosis. Angiology 2001; 52(8):521526. significant stenosis in the normal $\mathrm{Cx}$, an anomalous $\mathrm{Cx}$ arising from the $\mathrm{RCA}$, right sinus of Valsalva, or aorta should be suspected in a patient with acute inferior, posterior myocardial infarction or acute coronary syndrome [5]. Thus, the angiographer must always keep in mind this possibility.

\section{Consent}

Written informed consent was obtained from the patients for publication of these case reports. A copy of the written consent is available for review by the Editor-in-Chief of this journal.

\section{Competing interests}

The author(s) declare that they have no competing interests.
9. Coşansu K, Ağaç $M T$, Kılıç $H$, Akdemir R, Gündüz $\mathrm{H}$. Twin circumflex arteries: a rare coronary artery anomaly. J Tehran Heart Cent 2018;13(1):32-34.

10. Sinha SK, Mishra V, Abdali N, et al. Primary percutaneous coronary intervention angioplasty of occluded twin circumflex coronary artery in a patient of acute inferior wall myocardial infarction: a rare anomaly. Cardiol Research 2017; 8(2):52.

11. Kardos A, Babai L, Rudas L, et al. Epidemiology of congenital coronary artery anomalies: a coronary arteriography study on a central European population. Cath Cardiovasc Diagn 1997; 42(3):270-275.

12. Tuncer $C$, Batyraliev T, Yilmaz R, Gokce $M$, Eryonucu B, Koroglu S. Origin and distribution anomalies of the left anterior descending artery in 70,850 adult patients: multicenter data collection. Cath Cardiovasc Interv 2006; 68(4):574-585.

13. Spindola-Franko $H$, Grose $R$, Solomon M. Dual left anterior descending coronary artery: Angiographic description of important variants and surgical implications. Am Heart J 1983; 105:445-455.

14. Silverman KJ, Bulkley $\mathrm{BH}$, Hutchins $\mathrm{GM}$. Anomalous left circumflex coronary artery: "normal" variant of uncertain clinical and pathologic significance. Am J Cardiol 1978; 41:1311-1314.

15. Attar MN, Moore RK, Khan S. Twin circumflex arteries: a rare coronary artery anomaly. J Invasive Cardiol 2008; 20:E54-55. 
16. van der Velden LB, Bär FW, Meursing BT, Ophuis TJ. A rare combination of coronary anomalies. Neth Heart J 2008; 16:387-389.

17. Cicek D, Gokay S, Eldem HO, Muderrisoglu $\mathrm{H}$. Significant stenoses of twin circumflex arteries accompanied by heart failure: a rare coronary artery anomaly. Clin Pract 2011; $1: \mathrm{e} 22$.

18. Andreou AY, Theodorou S, Makrides C, Avraamides PC. Twin left circumflex arteries in a patient undergoing aortic valve replacement. Eur Rev Med Pharmacol Sci 2014; 18:71-73.

19. Otlu YÖ, Bayramolu A, Hidayet Ş, Ermiş N. Transradial percutaneous coronary intervention in a patient with a rare coronary anomaly: twin circumflex arteries. Acta Cardiol Sin 2015; 31:72-74. 